\title{
COMPARISON OF UAVS PERFORMANCE FOR A ROMAN AMPHITHEATRE SURVEY: THE CASE OF AVELLA (ITALY)
}

\author{
S. Barba ${ }^{a}$, M. Barbarella ${ }^{\mathrm{b}}$, A. Di Benedetto ${ }^{\mathrm{a}}$, M. Fiani ${ }^{\mathrm{a}}$, M. Limongiello ${ }^{\mathrm{a}}$ \\ ${ }^{a}$ Department of Civil Engineering, University of Salerno, Fisciano (SA), Italy \\ (sbarba; m.fiani; mlimongiello; adibenedetto)@unisa.it \\ ${ }^{\mathrm{b}}$ Department of Civil, Chemical, Environmental and Materials Engineering, University of Bologna, Bologna, Italy \\ maurizio.barbarella@unibo.it
}

\begin{abstract}
KEY WORDS: Archaeological mapping, Unmanned Aerial Vehicle, Terrestrial Laser Scanner, Georeferencing, 3D Model, Cloud
\end{abstract} comparison, Accuracy assessment.

\begin{abstract}
:
In the field of archaeological surveying, remote sensors and especially photogrammetric and laser scanner systems are widely used to create 3D models. The use of photogrammetric surveying with UAVs (Unmanned Aerial Vehicles), combined with Computer Vision algorithms, allows the building of three-dimensional models, characterized by photo-realistic textures. The choice of which method to use mainly depends on the complexity of the investigated site, the accuracy requirements and the available budget and time. The different components of the UAV system determine its characteristics in terms of performance and accuracy, therefore define its quality and the cost too. This study presents an assessment of the accuracy of point clouds derived by two UAV systems, a commercial quadcopter (DJI Phantom 3 Professional), a professional assembled hexacopter, and by a TLS (Terrestrial Laser Scanner) in order to compare photogrammetric and laser scanner data for archaeological applications. In this paper, we present a case study to compare and analyse the metric accuracy of the point clouds and the distribution of the GCPs (Ground Control Points). This accuracy assessment will serve to quantify the uncertainty in the absolute position of the GCPs, identified on the panoramic images in the absence of artificial targets. Executed experiments showed that in tested UAVs, the choice of the GCPs has significant impact on point cloud accuracy. Estimated absolute accuracy of point clouds collected during both test flights was better than $5 \mathrm{~cm}$.
\end{abstract}

\section{INTRODUCTION}

In the last few years, there has been an increasing demand in the digital documentation of archaeological sites (Bitelli et al., 2017; Striova and Pezzati, 2017), mainly for deformations analysis, restoration and conservation projects.

Especially in archaeological surveys, it is truly important to carry out a survey with 'high resolution' techniques that are also accurate, fast and quite inexpensive. Geomatics techniques allow to provide reliable metrical products needed for proper knowledge and representation of the heritage sites. In this field, remote sensors and especially photogrammetric and laser scanner systems are widely used to create digital elevation models (DEM).

Both systems have been successfully combined in a variety of applications, making the most of the inherent strengths of both approaches (Fritz et al., 2013, Jo and Kim, 2017; Takahashi et al., 2017). Terrestrial Laser Scanning (TLS) is a mature technique for the acquisition of point clouds, which allows to reconstruct a $3 \mathrm{D}$ model of the object. It represents an alternative to the traditional surveying techniques and allows the high-resolution capture of complex geometric shapes with great potential in the documentation and analysis of archaeological artefacts and sites. TLS technique has expanded widely with applications in many fields (GonzálezJorge et al. 2017), including historical/archaeological buildings or monuments (Guarnieri et al., 2017; Lambers and Remondino, 2008), architecture (Krishnan et al., 2011), infrastructures (Barbarella et al., 2018), building information modelling (BIM) (Chow and Fai, 2017; Thomson and Boehm, 2015) and many others.

In addition, the surveys by unmanned aerial vehicle (UAV) allow to obtain reliable 3D models (Colomina and Molina, 2014; Federman et al., 2017; Pajares, 2015; Remondino et al.,
2011). Thanks to their small weight and compact dimensions, it is possible to collect data without having ground based physical access to areas. In particular, aerial photogrammetry from UAV has been very used in archaeology and cultural heritage for 3D documentation and mapping of sites and structures, thanks to innovative low-cost systems and high resolution digital cameras (Brumana et al., 2013; Masiero et al., 2019; Mozas-Calvache et al., 2012; Nikolakopoulos et al., 2016; Sauerbier and Eisenbeiss, 2010).

Moreover, the use of photogrammetric surveys with UAV, combined with Computer Vision algorithms, allows the construction of 3D models, characterized by photorealistic textures (Barazzetti et al. 2014).

Software tools based on algorithms like Structure-from-Motion and multi-view stereo image matching enable the fully automatic generation of densely meshed 3D point clouds (Georgopoulos et al., 2016). As both TLS and photogrammetry technique have advantages and disadvantages, the choice is generally based on the project's budget and less on objectives or the required level of detail. The photogrammetric techniques require experience otherwise the results may be incorrect. The TLS, instead, is not so difficult to use, but it requires experience on settings of parameters and activities extremely timeconsuming, and cost-intensive.

The choice of which method to use mainly depends on the complexity of the investigated site, the accuracy requirements and the available budget and time (Lambers and Remondino, 2008). Hence, often it has required the integration of more techniques (Eisenbeiss and Zhang, 2006; Lerma et al., 2010). To achieve the required high-resolution level, all phases of the survey must be accurate. As for the correctness of 3D UAV models, camera calibration (Cramer et al., 2017; Fraser and Stamatopoulos, 2014) and georeferencing (He et al., 2018; Padró et al., 2019) play an important role in the final accuracy 
of the results. Other factors are camera resolution, flight height and GCPs (ground control points) accuracy (Ruzgienè et al., 2015; Suzuki et al., 2016; Zimmermann, 2017)

Besides, in TLS surveying, scan registration and georeferencing are two essential steps and their accuracy determines the goodness of 3D final models (Fan et al., 2015).

There are many types of UAV systems available in the commercial market. All of them have their advantages and disadvantages including their suitability to some kind of applications. The different components of the UAV systems determine their characteristics in terms of performance and accuracy, therefore, they define their quality and cost as well. According to this criterion, the UAVs can be divided into 'commercial' or 'professional' vehicles.

The present paper is aimed to test the characteristic in terms of image quality and accuracy evaluation of the point cloud collected with two UAV systems in archaeological applications by conducting a specific case study. The test site chosen was the Avella Amphitheatre.

To assess the accuracy of the results we compared the 3D model obtained by a commercial UAV with a maximum take-off weight of up to $2.0 \mathrm{~kg}$ with that obtained by a professional assembled UAV. Both UAV surveys are also compared with a high resolution TLS survey.

\section{CASE STUDY}

The case study refers to the Roman Amphitheatre of Avella (Figure 1), in the Campania Region (Limongiello et al., 2016; Barba et al., 2019).

It is located on the southeast corner of the ancient Roman walls where the orientation of the major axis, southwest/northeast, varies from the grid of the ancient orthogonal city. The structure incorporates part of the walls (on the southeast corner) and a natural slope (on the west side).

The main characteristic of this type of buildings is to be able to adapt to natural conditions of the ground, so the cavea is totally or partially excavated in the ground or in the rock. The arrangement of the Amphitheatre consists externally of two semi-circular structures connected by walls at right angle, and internally in an oval-shaped structure, the arena. Its dimensions are $63.6 \times 34.3 \mathrm{~m}$.

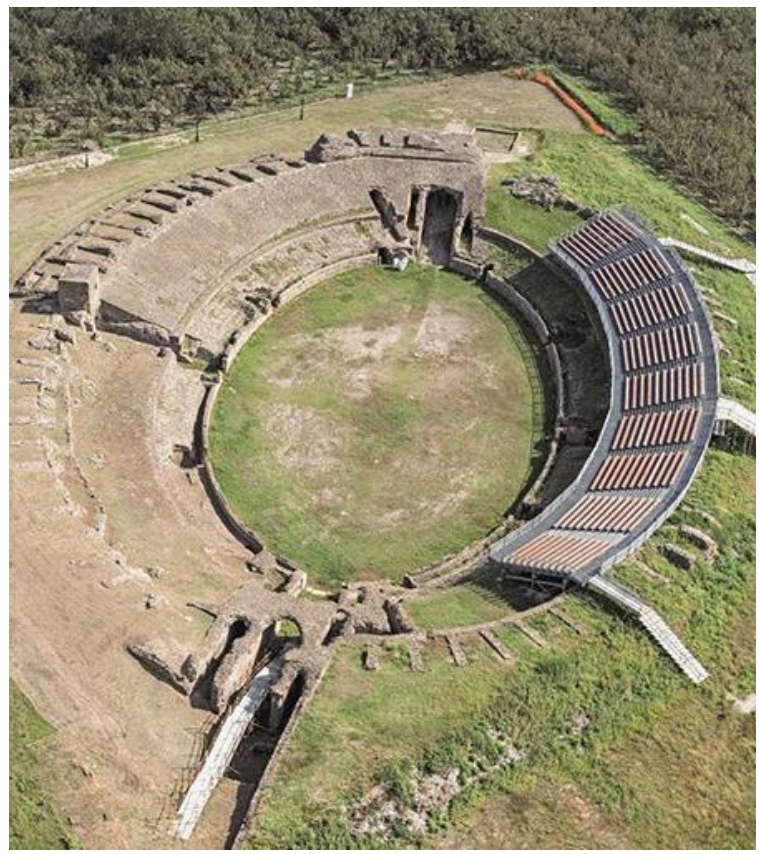

Figure 1. Case study: the Roman Amphitheatre in Avella

\section{DATA ACQUISITION AND PROCESSING}

\subsection{Photogrammetric survey by UAVs}

The photogrammetric surveys were performed using two different UAV systems (Figure 2):

- a professional assembled hexacopter ;

a commercial DJI Phantom 3 Professional quadcopter.

A vertical take-off and landing system, commonly known as a "multicopter", in particular a hexacopter, was used for the first survey. The digital camera, a Sony Nex 7 , is mounted on a servo-assisted support that allows an electronically controlled rotation. The nadiral images were acquired in time-lapse $(2 \mathrm{sec}$.) mode by automatic flight plan.

Another UAV used was the DJI Phantom 3 Professional, also a multicopter, but a quadcopter. The DJI Phantom 3 Professional is lightweight and relatively low-cost, but it is not geared for close-range inspection tasks.

The DJI Phantom 3 Professional is able to shoot video in $4 \mathrm{~K}$ and streaming HD videos on smartphones, tablets and external devices through a special App (DJI Go). The camera is integrated in the gimbal to maximize the stability of the images during the movement. The nadiral images are acquired in manual mode. A few specifications about the UAVs and the surveys are summarized in Table 1.

Figure 3 shows the camera positions of the two flights.

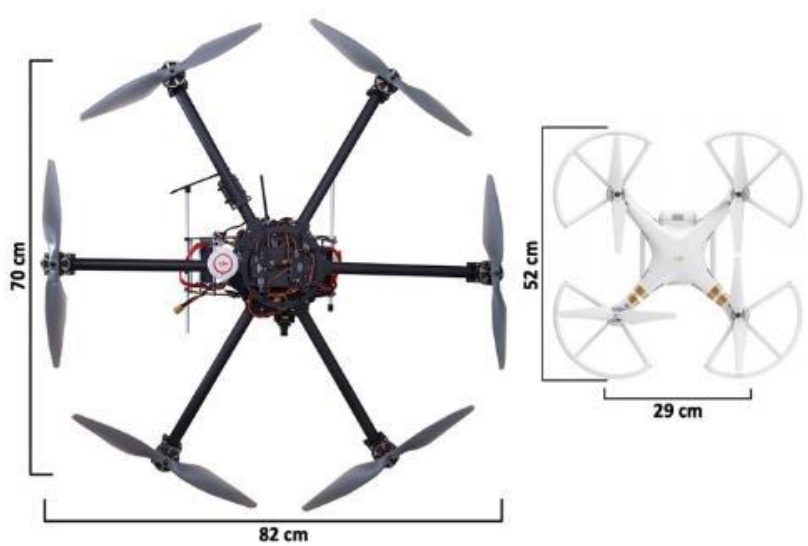

Figure 2: Hexacopter and DJI Phantom 3 Professional

\begin{tabular}{|c|c|c|c|c|}
\hline \multicolumn{5}{|c|}{ HEXACOPTER } \\
\hline weight & payload & flight plan & flight dir & flight height \\
\hline $2.3 \mathrm{~kg}$ & $1 \mathrm{~kg}$ & automatic & NW-SE & $32 \mathrm{~m}$ \\
\hline camera & sensor & sensor size & resolution & focal length \\
\hline Sony Nex7 & APS-C CMOS & $23.5 \times 15.7 \mathrm{~mm}$ & $24 \mathrm{MP}$ & $16 \mathrm{~mm}$ \\
\hline FOV & \# images & time-laps & pixel size & $G S D$ \\
\hline $83^{\circ}$ & 435 & $2 \mathrm{sec}$ & $4 \square$ & $7.92 \mathrm{~mm}$ \\
\hline \multicolumn{5}{|c|}{ DJI PHANTOM 3 PROFESSIONAL QUADCOPTER } \\
\hline weight & payload & flight plan & flight dir & flight height \\
\hline $1.3 \mathrm{~kg}$ & - & automatic & NW-SE & $32 \mathrm{~m}$ \\
\hline camera & sensor & sensor size & resolution & focal length \\
\hline Sony & CMOS Exmor & $6.3 \times 4.7 \mathrm{~mm}$ & $12.4 \mathrm{MP}$ & $4 \mathrm{~mm}$ \\
\hline FOV & \# images & time-laps & pixel size & $G S D$ \\
\hline $94^{\circ}$ & 75 & waypoint & $1,55 \square$ & $12.4 \mathrm{~mm}$ \\
\hline
\end{tabular}

Table 1. UAVs and cameras specifications and survey planning 

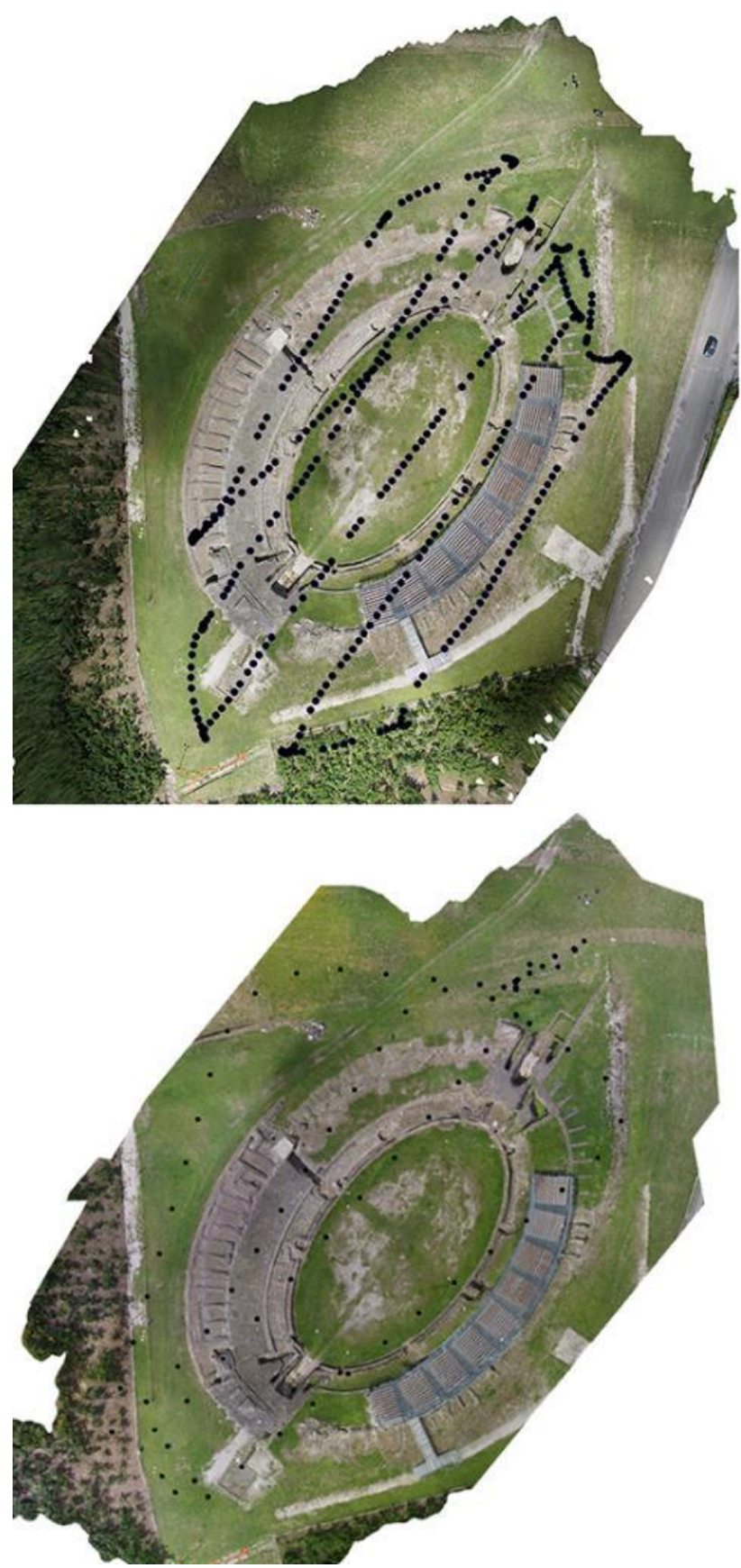

Figure 3: Nadir flight camera positions. Upper panel: hexacopter; bottom panel: DJI Phantom 3 Professional

In order to process the photogrammetric data, PhotoScan software package by Agisoft (ver. 1.4.2 build 4164) was used (Agisoft, 2016). The following parameters were set for the processing of point clouds: in the 'Align Photos' phase, Accuracy $=$ High (original images), Key-Point limit $=4000$, Tie-Point limit $=4000$. To optimize camera alignment process, $\mathrm{f}$ (focal length), $\mathrm{c}_{\mathrm{x}}$ and $\mathrm{c}_{\mathrm{y}}$ (principal point offset), k1, k2, k3, k4 (radial distortion coefficients), were fitted. In the computation of the Dense Cloud, the parameters used were: Quality = High (1/4 of the original images), Depth filtering = Disable; once the complete elaboration of the photogrammetric shots was done, the software gave back the texturized 3D model of the Avella Amphitheatre, used to extract the orthophoto.

The phases of co-registration of the twenty scans and global alignment were carried out using Faro® Scene 2019 software package (FARO SCENE, 2019) using the 'Cloud to Cloud' automatic registration and ICP algorithm. Georeferencing was made using PointCab software package, ver. 3.8 release 4 (PointCab, 2018) by Point Cloud software Company, as well as the Check Points (CPs) analysis too.

\subsection{TLS Survey}

For the TLS survey we used the Cam2 Focus X130 HDR by Faro (range $0.6 \mathrm{~m}-130 \mathrm{~m}$, max measurement speed 976.000 points/sec, HDR integrated camera, vertical Field of view $300^{\circ}$, horizontal FOV $360^{\circ}$ ). We have acquired twenty scans (Figure 4 ), of which nine to survey the arena and the vertical walls, with an average density between 100 and 350 points $/ \mathrm{dm}^{2}$. The remaining eleven scans have an average density between 700 and 1400 points $/ \mathrm{dm}^{2}$. The latter have much greater density because are acquired in correspondence of the natural targets used as GCPs in the georeferencing phase.

\subsection{GNSS Survey}

For georeferencing of both the photogrammetric and the TLS point clouds, a number of GCPs were measured on the amphitheatre, by GNSS (Global Navigation Satellite Systems) double-frequencies receivers, a Geomax Zenith 25 and a Trimble 5700 with antenna Zephir. As GCPs we have chosen a few natural (well defined) targets and surveyed in two different modalities: eight points in fast - static and seventeen points in nRTK (near Real Time Kinematic) modalities. Among the latter are the eight points measured in fast-static too. In Figure 5, the position of the GCPs is shown. The GNSS survey refers to the Italian geodetic and cartographic System UTM/ETRF00 (Barbarella, 2014) through a connection to two permanent stations (AVEL and ROBS) included in the national Geodetic Network located within a radius of $10 \mathrm{~km}$ from the test area. A new point (master) has been materialized near the Amphitheatre and connected to the permanent stations with static baselines. We made 5-hours-long sessions to connect the master station with the permanent stations.

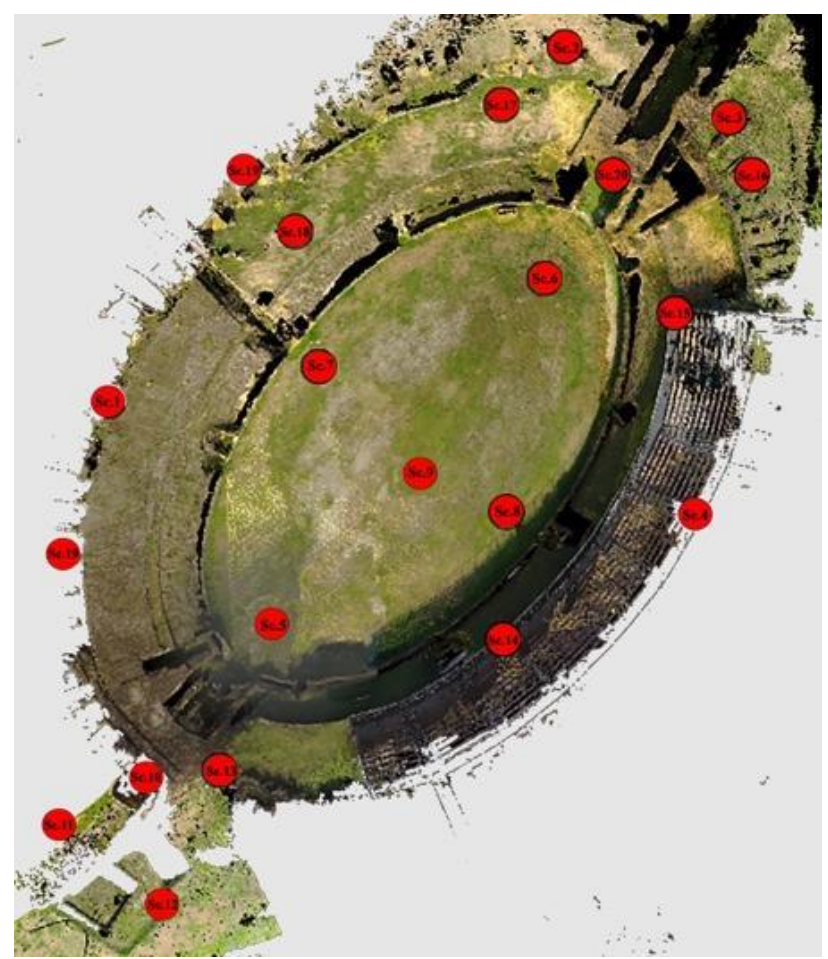

Figure 4. TLS Scan Station positions 


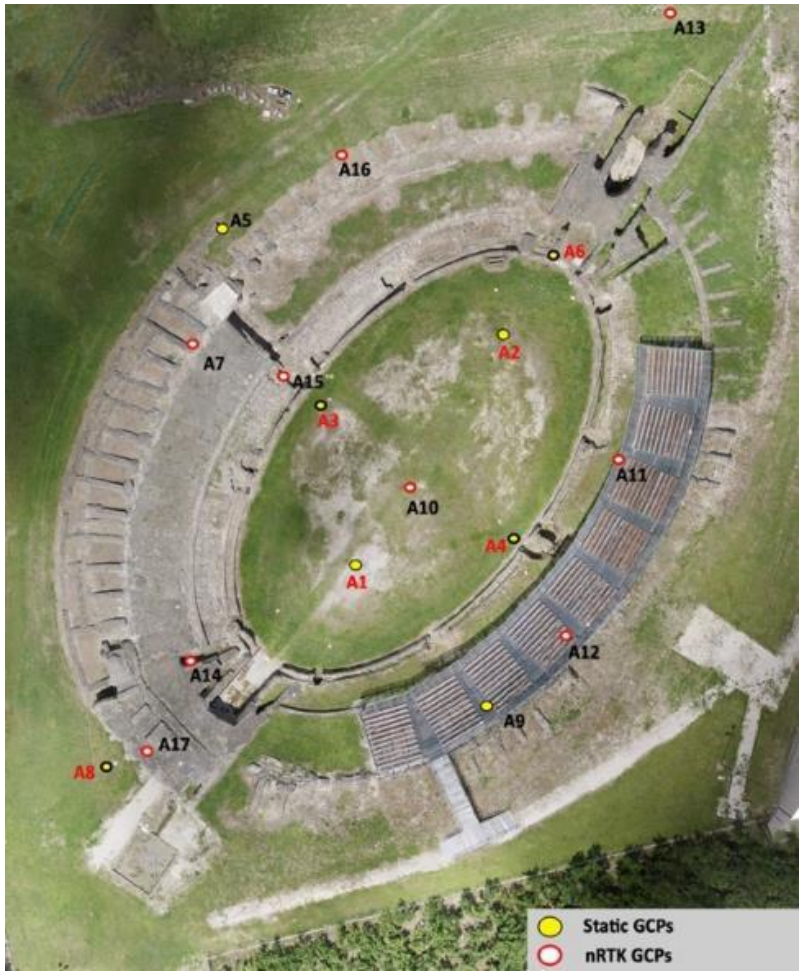

Figure 5. GCPs position

The processing of GNSS static baselines was carried out using the Geo Office ver. 3.21 software package, by Geomax (Geo Office, 2016). The resulting RMS in the computation of the baselines was in the order of $4 \div 5 \mathrm{~mm}$ in planimetry and $12 \mathrm{~mm}$ in height.

\section{DATA ANALYSIS AND DISCUSSION}

\subsection{UAV images processing}

Once the photogrammetric model was formed, we georeferenced the block, using the coordinates of the seventeen natural targets measured in nRTK modality; the software provides residual values on GCPs.

In the samples, a few outliers are present, therefore the residuals greater than twice the SD - Standard Deviation (corresponding to the significance level of $5 \%$ ) have been removed one by one from the set and the statistical parameters have been recomputed. For the point cloud by DJI Phantom3, three points have been removed whereas for the point cloud by the hexacopter only one. In Tables $2 a$ ) and 2 b) the residual values for the two UAVs are reported, divided by components, once the outliers have been removed.

\subsection{TLS processing}

The twenty TLS scans were co-registered and subsequently aligned to build a global point cloud of the amphitheatre. The total point cloud has about 2 billion points. For the coregistration between scans, the mean point error on the reference pairs ranges between 4 and $14 \mathrm{~mm}$ whereas the standard deviation about the final global alignment is less than 9 $\mathrm{mm}$.

A number of georeferencing tests have been done with the PointCab software using separately the GCPs surveyed in faststatic and in nRTK mode. Tables $4 \mathrm{a}$ and $4 \mathrm{~b}$ show the georeferencing results for both the sets of GCPs.

Not all the points measured on the ground are clearly visible and collimable on the TLS point cloud.

Subsequently other points were removed, because the georeferencing residuals were too high. In better details, in Table $4 \mathrm{a}$ are reported the residues obtained using four or six GCPs measured in fast-static whereas in Table $4 \mathrm{~b}$ the residues for the GCPs measured in nRTK.

\begin{tabular}{cccc}
\hline \multicolumn{5}{c}{ Hexacopter - Residuals (cm) } \\
\hline GCP & $\mathrm{E}$ & $\mathrm{N}$ & $\mathrm{h}$ \\
\hline $\mathrm{A} 1$ & -1.7 & 1.6 & 0.3 \\
\hline $\mathrm{A} 2$ & -2.5 & 1.1 & 0.3 \\
\hline $\mathrm{A} 3$ & 1.2 & -2.8 & -0.5 \\
\hline $\mathrm{A} 4$ & -3.2 & 0.6 & 0.6 \\
\hline $\mathrm{A} 5$ & 0.8 & -0.8 & 0.7 \\
\hline A7 & -0.2 & -1.5 & 0.6 \\
\hline A8 & -0.4 & 1.2 & -0.8 \\
\hline A9 & -0.5 & -0.3 & 0.3 \\
\hline A10 & 1.8 & 0.5 & 0.5 \\
\hline A11 & 0.9 & 1.5 & 0.9 \\
\hline A12 & 0.4 & 0 & -0.3 \\
\hline A13 & 0.7 & 0.6 & 0.4 \\
\hline A14 & -0.7 & -3.0 & -0.1 \\
\hline A15 & 1.2 & 2.6 & -1.5 \\
\hline A16 & 0.7 & -0.4 & -0.8 \\
\hline A17 & 0.3 & -0.4 & 0.6 \\
\hline
\end{tabular}

Table 3a. Georeferencing residuals on GCPs measured in nRTK modality for hexacopter

\begin{tabular}{cccc}
\hline \multicolumn{4}{c}{ DJI PHANTOM 3 Professional - Residuals (cm) } \\
\hline GCP & E & $\mathrm{N}$ & $\mathrm{h}$ \\
\hline $\mathrm{A} 1$ & -5.3 & -2.5 & -0.3 \\
\hline $\mathrm{A} 2$ & -4.2 & 0.4 & -1.2 \\
\hline $\mathrm{A} 3$ & 0.7 & -8.6 & 1.0 \\
\hline $\mathrm{A} 4$ & 0.3 & -1.3 & 0.4 \\
\hline $\mathrm{A} 6$ & 9.4 & -2.5 & -1.3 \\
\hline $\mathrm{A} 8$ & -1.0 & -0.5 & 4.3 \\
\hline $\mathrm{A} 9$ & -7.9 & 0.6 & -0.9 \\
\hline $\mathrm{A} 10$ & 2.1 & 3.1 & 1.6 \\
\hline $\mathrm{A} 11$ & -1.9 & 4.7 & -0.5 \\
\hline $\mathrm{A} 12$ & -4.4 & 3.5 & -0.3 \\
\hline $\mathrm{A} 14$ & -3.8 & -9.3 & 0.8 \\
\hline $\mathrm{A} 15$ & -1.4 & -4.2 & -3.1 \\
\hline A16 & 1.5 & -6.7 & 2.7 \\
\hline A17 & -2.6 & -4.5 & -2.3 \\
\hline
\end{tabular}

Table $3 b$. Georeferencing residuals on GCPs measured in nRTK modality for Phantom 3 Professional

\begin{tabular}{ccccc}
\hline \multicolumn{5}{c}{ TLS - Residuals using 4 GCPs $(\mathbf{c m})$} \\
\hline GCP & $\mathrm{E}$ & $\mathrm{N}$ & $\mathrm{h}$ & \\
\hline $\mathrm{A} 1$ & 0.2 & -0.3 & 0.4 & 0.5 \\
\hline $\mathrm{A} 3$ & 0.0 & 0.1 & 0.1 & 0.1 \\
\hline $\mathrm{A} 4$ & -0.6 & -0.1 & -0.1 & 0.6 \\
\hline $\mathrm{A} 8$ & 0.4 & 0.3 & -0.2 & 0.5 \\
\hline \multicolumn{5}{c}{ TLS - Residuals using 6 GCPs $(\mathbf{c m})$} \\
\hline A1 & 0.1 & -0.6 & 0.2 \\
\hline A2 & -0.2 & -0.6 & 2.4 & 0.6 \\
\hline A3 & 0.2 & 0.2 & 0.1 & 0.5 \\
\hline A4 & -0.6 & 0.2 & -0.3 & 0.7 \\
\hline A6 & 0.2 & 0.4 & -2.0 & 2.1 \\
\hline A8 & 0.3 & 0.3 & -0.4 & 0.6 \\
\hline
\end{tabular}

Table 4a. Georeferencing residuals on GCPs measured in faststatic mode for TLS

TLS - Residuals using 6 GCPs (cm) 


\begin{tabular}{ccccc}
\hline GCP & E & $\mathrm{N}$ & $\mathrm{h}$ & \\
\hline $\mathrm{A} 1$ & -1.0 & 0.2 & -0.5 & 1.2 \\
\hline $\mathrm{A} 2$ & 0.6 & 0.9 & -1.0 & 1.4 \\
\hline $\mathrm{A} 3$ & 0.4 & 13.0 & 0.8 & 1.0 \\
\hline $\mathrm{A} 8$ & 0.0 & 0.4 & -0.1 & 0.4. \\
\hline $\mathrm{A} 10$ & 0.7 & 0.1 & 1.2 & 1.4 \\
\hline $\mathrm{A} 15$ & -0.7 & -1.6 & -0.5 & 1.8 \\
\hline
\end{tabular}

Table 4b. Georeferencing residuals on GCPs measured in nRTK mode for TLS

Thereafter, still using PointCab software, the coordinates of the remaining points measured on the ground, here used as Check Points, have been compared with the corresponding ones measured on the point cloud. This allows us to carry out a comparison based on the dispersion of the CPs residuals among point clouds georeferenced using both different GNSS modality and different number of GCPs. Table 5 shows the values of the Check-Point standard deviations obtained after performing the analysis for various different scenarios (for both the photogrammetric and TLS data). Observing the dispersion of the CPs it is clear that the values of SDs for the DJI Phantom 3 (3-4 cm in planimetry, about 1.5 in height) are more than double than the hexacopter ones $(1-2 \mathrm{~cm}$ in planimetry, less than $1 \mathrm{~cm}$ in height).

For the TLS, the SD values in planimetry is smaller than the corresponding values for the hexacopter, whereas in height the dispersion is closer to that of the DJI Phantom 3. These results make the survey with TLS (high density) comparable with the photogrammetric survey with a performing UAV as the hexacopter. The survey made with a commercial UAV as the Phantom 3 produced significantly less accurate results. This result need to be confirmed in other tests.

\begin{tabular}{ccccc}
\hline \multicolumn{5}{c}{ Standard Deviation (mm) } \\
\hline & $\mathrm{n}^{\circ}$ GCPs - survey mode & $\mathrm{E}$ & $\mathrm{N}$ & $\mathrm{h}$ \\
\hline \multirow{3}{*}{ TLS } & 4 Fast-static & 9 & 12 & 15 \\
\cline { 2 - 5 } & 6 Fast-static & 5 & 10 & 13 \\
\cline { 2 - 5 } & $6 \mathrm{nRTK}$ & 7 & 8 & 8 \\
\hline \multirow{2}{*}{$\begin{array}{c}\text { DJ Phantom } 3 \\
\text { Professional }\end{array}$} & $10 \mathrm{nRTK}$ & 25 & 35 & 15 \\
\cline { 2 - 5 } & $14 \mathrm{nRTK}$ & 42 & 44 & 19 \\
\hline \multirow{2}{*}{ Hexacopter } & $10 \mathrm{nRTK}$ & 15 & 19 & 4 \\
\cline { 2 - 5 } & $16 \mathrm{nRTK}$ & 14 & 15 & 7 \\
\hline
\end{tabular}

Table 5. Comparison of CPs SD in various scenarios

\subsection{Comparison between models}

It is worth to evaluate which differences are found between the point clouds obtained on the entire amphitheatre. The differences between the 3D models have been computed using the 'Cloud Compare' open software (CloudCompare, 2018). In better details, we used the 'Cloud-to-Cloud Distance computation' tool and the 'Local modelling function' in order to compute the distances between two point clouds that are not equally dense. A TIN (Triangulated Irregular Network) DEM (Digital Elevation Model) is built using Delaunay triangulation; this is the reference cloud. The orthogonal distance between each point of the cloud to compare and the nearest triangle in the reference mesh is computed. Afterwards, a raster grid has been created using Cloud Compare 'Tools > Projection > Rasterize menu and then exported as a raster image (geotiff). The main (raster) grid generation parameters we chose are: - grid step size: $5 \mathrm{~cm}$; projection direction: $\mathrm{Z}$;

how the 'height' of each cell grid will be computed: average height of all points falling in this cell.

Moreover, if no points fall inside a given cell, this cell will be considered as 'empty'. Finally, the raster image has been classified using ArcMap ver. 10.2.1 software GIS by Esri.

Figures $6 a, b, c$ show the classified maps of the differences, represented by a chromatic scale; the areas without data have been classified as "No Data".

A first comparison was made between the two 3D models obtained from the UAVs (Figure 6a), both georeferenced with similar number of GCPs surveyed in nRTK. The main differences are in correspondence of the metal tiers (East area), probably due to the reflecting material, and in correspondence of some vertical walls. Subsequently, the photogrammetric models were compared with the reference TLS point cloud (Figures $6 \mathrm{~b}$ and $6 \mathrm{c}$, respectively).

On the arena floor and on the cavea the differences are a few centimetres (1-4), whereas higher values $(5-10 \mathrm{~cm})$ are present in the recessed areas (entrances, curbs) and higher values, up to $20 \mathrm{~cm}$ in some areas of the covers. In the northeast area of the arena and near the vertical walls there is an area characterized by differences greater than $15 \mathrm{~cm}$, this for both photogrammetric models. In Figure 6d, it is possible to observe the differences in the profiles. They are probably mainly due to both the presence of dense vegetation, absent in the TLS scans, and the loose material accumulated at the border of the arena. The flat areas without vegetation show very low differences (less than 3-4 cm) while the differences are greater along the vertical faces and areas with sharp variations in height.

The point of view position with respect to the object (nadiral for the UAV images, 'panoramic' or frontal for the TLS) plays an important role in the results. Similar evaluations can also be applied to the comparison between DJI Phantom 3 Professional and TLS (shown in Figure 6c). These differences, although slightly higher, are still less than $5 \mathrm{~cm}$ on average.

\section{CONCLUSIONS}

A few 3D models of the Amphitheatre were built from both photogrammetric and terrestrial laser-scanning data.

The high density TLS point cloud well describes the vertical structures, whereas for the reconstruction of the planar geometry of the amphitheatre, TLS is not the most suitable instrument due to the difficult to scan the horizontal planes placed at different heights. In order to make a sensible comparison between TLS survey and the photogrammetric ones by UAVs, these latter should produce high-density point clouds. For this reason, as well as to improve the accuracy of the aerial photogrammetric survey, it is often necessary to use oblique images in addition to the nadiral ones. The purpose of this study was to verify the performance of a lightweight and relatively lowcost UAV, using natural points as GCPs, in respect to a more reliable hexacopter. The use of a professional UAV, compared to a less performing system, allows to obtain a better photogrammetric model. The professional assembled hexacopter, compared with the commercial UAV, certainly allows to produce a better $3 \mathrm{D}$ object model, even if the non-professional UAV produced results compatible with the representation scale commonly used for the planimetry too. The comparisons with 3D models by TLS are needed to assess the accuracy of the photogrammetric models. By analysing the photogrammetric surveys in respect to the TLS point clouds, the average differences between the cloud produced by a hexacopter equipped with a camera fitted with APS-C sensor, are about $5 \mathrm{~cm}$, whereas for the commercial vehicle, equipped with a smaller sensor, the differences are bigger, about $8 \mathrm{~cm}$. 

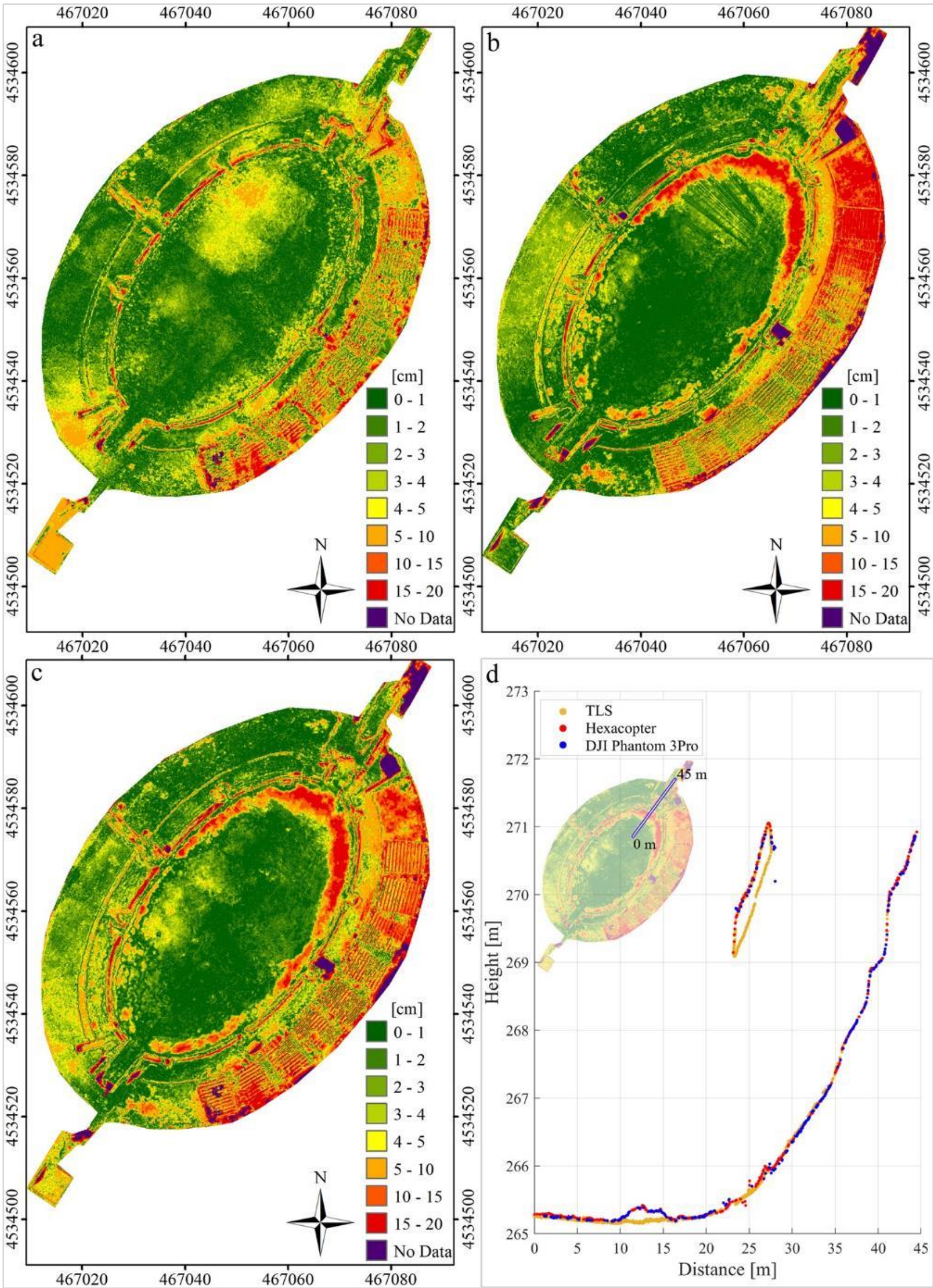

Figure 6. Comparisons between 3D models derived from photogrammetric and TLS surveys.

Panel a: Phantom vs Hexacopter; panel b: Hexacopter vs TLS; panel c: Phantom vs TLS. Panel d: section 


\section{REFERENCES}

Agisoft LLC, 2017. Agisoft PhotoScan User Manual. Version 1.3, Agisoft, 105.

Barazzetti, L., Brumana, R., Oreni, D., Previtali, M., Roncoroni, F., 2014. True-orthophoto generation from UAV images: Implementation of a combined photogrammetric and computer vision approach. ISPRS Ann. Photogramm. Remote Sens. Spatial Inf. Sci., II-5, 57-63.

Barba, S., Barbarella, M., Di Benedetto, A., Fiani, M., Limongiello, M., 2019. Quality assessment of uav photogrammetric archaeological survey. Int. Arch. Photogramm. Remote Sens. Spatial Inf. Sci., XLII-2/W9, 93100.

Barbarella, M., 2014. Digital technology and geodetic infrastructures in Italian cartography, Città e Storia, Volume 9, Issue 1, 91-110.

Barbarella, M., D’Amico, F., De Blasiis, M., Di Benedetto, A., Fiani, M., 2018. Use of Terrestrial Laser Scanner for Rigid Airport Pavement Management. Sensors, 18, 44.

Barber, D., Mills, J., English, H., 2007. 3D laser scanning for heritage: advice and guidance to users on laser scanning in archaeology and architecture. English Heritage.

Bitelli, G., Balletti, C., Brumana, R., Barazzetti, L., D’Urso, M.G., Rinaudo, F., Tucci, G., 2017. Metric documentation of cultural heritage: research directions from the italian gamher project. Int. Arch. Photogramm. Remote Sens. Spatial Inf. Sci., XLII-2/W5, 83-90.

Brumana, R., Oreni, D., Van Hecke, L., Barazzetti, L., Previtali, M., Roncoroni, F., Valente, R., 2013. Combined geometric and thermal analysis from uav platforms for archaeological heritage documentation. ISPRS Ann. Photogramm. Remote Sens. Spatial Inf. Sci., II-5/W1, 49-54.

Chow, L. and Fai, S., 2017. Developing verification systems for building information models of heritage buildings with heterogeneous datasets. Int. Arch. Photogramm. Remote Sens. Spatial Inf. Sci., XLII-2/W5, 125-128.

Colomina, I. and Molina, P., 2014. Unmanned aerial systems for photogrammetry and remote sensing: A review. ISPRS Journal of Photogrammetry and Remote Sensing 92, 79-97.

Cramer, M., Przybilla, H.J., Zurhorst, A., 2017. UAV cameras: overview and geometric calibration benchmark Int. Arch. Photogramm. Remote Sens. Spatial Inf. Sci., XLII2/W6, 85-92.

Eisenbeiss, H. and Zhang, L., 2006. Comparison of DSMs generated from mini UAV imagery and terrestrial laser scanner in a cultural heritage application, ISPRS Ann. Photogramm. Remote Sens. Spatial Inf. Sci., XXXVI-5, 9096.

Fan, L., Smethurst, J.A., Atkinson, P.M., Powrie, W., 2015. Error in target-based georeferencing and registration in Terrestrial Laser Scanning. Computers \& Geosciences 83, 54-64.

Federman, A., Santana Quintero, M., Kretz, S., Gregg, J.,
Lengies, M., Ouimet, C., Laliberte, J., 2017. UAV photgrammetric workflows: a best practice guideline. Int Arch. Photogramm. Remote Sens. Spatial Inf. Sci., XLII2/W5, 237-244.

FARO SCENE, 2019. FARO SCENE User Manual. Version 2019, FARO SCENE, 350

Fraser, C.S. and Stamatopoulos, C., 2014. Automated targetfree camera calibration, Proceedings of the ASPRS 2014 Annual Conference Proceedings, Louisville, KY, USA.

Fritz, A., Kattenborn, T., Koch, B., 2013. UAV-based photogrammetric point clouds-Tree stem mapping in open stands in comparison to terrestrial laser scanner point clouds. Int. Arch. Photogramm. Remote Sens. Spat. Inf. Sci., 40, 141-146.

GeoMax, 2016. Geo Office Software Operating Manual. Version 3.20, GeoMax, 530

Georgopoulos, A., Oikonomou, C., Adamopoulos, E., Stathopoulou, E.K., 2016. Evaluating unmanned aerial platforms for cultural heritage large scale mapping. Int. Arch. Photogramm. Remote Sens. Spatial Inf. Sci., XLI-B5, 355-362.

GitHub Inc., 2018. CloudCompare 2.8.1 User Manual. Version 2.9, GitHub Inc., 181.

González-Jorge, H., Martínez-Sánchez, J., Bueno, M., 2017. Unmanned aerial systems for civil applications: A review. Drones, 1, 2

Guarnieri, A., Fissore, F., Masiero, A., Vettore, A., 2017. from TLS survey to 3D solid modeling for documentation of built heritage: the case study of Porta Savonarola in Padua. Int. Arch. Photogramm. Remote Sens. Spatial Inf. Sci., XLII2/W5, 303-308.

He, F., Zhou, T., Xiong, W., Hasheminnasab, S.M., Habib, A., 2018. Automated Aerial Triangulation for UAV-Based Mapping. Remote Sensing, 10, 1952.

Jo, Y.H. and Kim, J.Y., 2017. Three-dimensional digital documentation of heritage sites using Terrestrial Laser Scanning and unmanned aerial vehicle photogrammetry. Int. Arch. Photogramm. Remote Sens. Spatial Inf. Sci., XLII2/W5, 395-398.

Krishnan, S., Crosby, C., Nandigam, V., Phan, M., Cowart, C., Baru, C., Arrowsmith, R., 2011. OpenTopography: a services oriented architecture for community access to LIDAR topography, Proceedings of the 2 nd International Conference on Computing for Geospatial Research \& Applications. ACM, Washington, DC, USA, pp. 1-8.

Lambers, K. and Remondino, F., 2008. Optical 3D measurement techniques in archaeology: recent developments and applications, Computer Applications and Quantitative Methods in Archaeology (CAA), pp. 27-35.

Laserscanning Europe GmbH, 2018. User Manual PointCab. Version 3.8-R4, Laserscanning Europe GmbH, 41.

Lerma, J.L., Navarro, S., Cabrelles, M., Villaverde, V., 2010. Terrestrial Laser Scanning and close range 
photogrammetry for 3D archaeological documentation: the Upper Palaeolithic Cave of Parpalló as a case study. Journal of Archaeological Science, 37, 499-507.

Limongiello, M., Santoriello, A., Schirru, G., Bonaudo, R., Barba, S., 2016. The Amphitheatre of Avella: from its origin to digital, IMEKO International Conference on Metrology for Archaeology and Cultural Heritage, Torino, pp. 19-21.

Masiero, A., Chiabrando, F., Lingua, A.M., Marino, B.G., Fissore, F., Guarnieri, A., Vettore, A., 2019. 3D modeling of Girifalco Fortress. Int. Arch. Photogramm. Remote Sens. Spatial Inf. Sci., XLII-2/W9, 473-478.

Mozas-Calvache, A.T., Pérez-García, J.L., CardenalEscarcena, F.J., Mata-Castro, E., Delgado-García, J., 2012. Method for photogrammetric surveying of archaeological sites with light aerial platforms. Journal of Archaeological Science, 39, 521-530.

Nikolakopoulos, K.G., Soura, K., Koukouvelas, I.K., Argyropoulos, N.G., 2017. UAV vs classical aerial photogrammetry for archaeological studies. Journal of Archaeological Science: Reports, 14, 758-773.

Padró, J.-C., Muñoz, F.-J., Planas, J., Pons, X., 2019. Comparison of four UAV georeferencing methods for environmental monitoring purposes focusing on the combined use with airborne and satellite remote sensing platforms. International Journal of Applied Earth Observation and Geoinformation, 75, 130-140.

Pajares, G., 2015. Overview and Current Status of Remote Sensing Applications Based on Unmanned Aerial Vehicles (UAVs). Photogrammetric Engineering \& Remote Sensing, 81, 281-330.

Remondino, F., Barazzetti, L., Nex, F., Scaioni, M., Sarazzi, D., 2011. UAV photogrammetry for mapping and $3 \mathrm{~d}$ modeling-current status and future perspectives. International archives of the photogrammetry, remote sensing and spatial information sciences, 38, C22.

Ruzgienè, B., Berteška, T., Gečyte, S., Jakubauskienė, E., Aksamitauskas, V.Č., 2015. The surface modelling based on UAV Photogrammetry and qualitative estimation. Measurement, 73, 619-627.

Sauerbier, M. and Eisenbeiss, H., 2010. UAVs for the documentation of archaeological excavations. Int. Arch. Photogramm. Remote Sens. Spat. Inf. Sci., 38.

Striova, J. and Pezzati, L., 2017. The European Research Infrastructure for Heritage Science (erihs). The International Archives of Photogrammetry, Remote Sensing and Spatial Information Sciences, 42, 661 .

Suzuki, T., Takahashi, Y., Amano, Y., 2016. Precise UAV position and attitude estimation by multiple GNSS receivers for 3D mapping, in: GNSS, I. (Ed.), 29th International Technical Meeting of the Satellite Division of the Institute of Navigation, pp. 1455-1464.

Takahashi, N., Wakutsu, R., Kato, T., Wakaizumi, T., Ooishi, T., Matsuoka, R., 2017. Experiment on UAV photogrammetry and Terrestrial Laser Scanning for ictintegrated construction. Int. Arch. Photogramm. Remote
Sens. Spatial Inf. Sci., XLII-2/W6, 371-377.

Thomson, C. and Boehm, J., 2015. Automatic Geometry Generation from Point Clouds for BIM. Remote Sensing, 7, 11753.

Zimmermann, F., Eling, C., Klingbeil, L., Kuhlmann, H., 2017. Precise positioning of UAVs - dealing with challenging rtk-gps measurement conditions during automated UAV flights. ISPRS Ann. Photogramm. Remote Sens. Spatial Inf. Sci., IV-2/W3, 95-102. 